\title{
Modelos de assistência obstétrica concorrentes e ativismo pela humanização do parto
}

\author{
Competing obstetric care models and activism \\ for humanization of parturition
}

Sara Sousa Mendonça*

\begin{abstract}
Resumo: Este artigo se dedica à análise do embate contemporâneo em torno da questão do parto: entre partidários do modelo "tecnocrático" e do "humanístico/humanizado" de assistência. Primeiramente ele se traduz em um embate entre defensores do parto normal e da cesárea, desacortinando o conflito entre estes dois modelos de assistência. Pretendo examinar os discursos médicos acerca de possíveis práticas obstétricas, com o objetivo de analisar como cada grupo (os que buscam legitimar o parto normal e os que defendem a cesárea) constrói e autoriza o seu discurso. Enfocarei o caminho percorrido pelos médicos formados em escolas de medicina com viés tecnocrático para a adoção do modelo humanizado. Analisarei também como as ativistas e demais mulheres se relacionam, respondem e se posicionam com relação a estes discursos médicos, considerando o papel desempenhado por elas como reprodutoras, legitimadoras e construtoras destes discursos.
\end{abstract}

Palavras-chave: Parto. Modelos médicos. Ativismo. Humanização.

Abstract: This article aims to analyze the contemporary conflict about the chidbirth: between supporters of the "technocratic" model and supporters of the "humanized" model of assistance. This is primarily a conflict between defenders of the normal birth and the caesarian section. I intend to examine the medical discourses about possible obstetric practices in order to analyze how each group (those who defend the normal birth and those who support the caesarian section) builds and authorizes his discourse. I will focus on the paths taken by physicians who studied in technocratic schools but adopted the humanized model. I will also analyze how activists and other women relate, respond and place themselves in relation to the medical discourses, considering the role played by them as reproducers and builders of these speeches.

Keywords: Childbirth. Medical models. Activism. Humanization.

\footnotetext{
* Mestre em Antropologia pela Universidade Federal Fluminense (UFF, Niterói, RJ, Brasil) e doutoranda em Antropologia na mesma universidade<sarasousa.me@gmail.com>.
} 
Este artigo se dedica à análise do embate contemporâneo em torno da questão do parto: entre partidários do modelo "tecnocrático" e do "humanístico/ humanizado" de assistência, que primeiramente se traduz em um embate entre defensores do parto normal e da cesárea, desacortinando o conflito entre estes dois modelos de assistência. Pretendo examinar os discursos médicos acerca de possíveis práticas obstétricas, com o objetivo de analisar como cada grupo (os que buscam legitimar o parto normal e os que defendem a cesárea) constrói e autoriza o seu discurso. Utilizo esta nomenclatura dos modelos de assistênciatecnocrático e humanístico/humanizado - enquanto categorias ao mesmo tempo analíticas (Davis-Floyd, 2003) e nativas, uma vez que a reflexão a respeito de sua própria prática e atuação no movimento pela humanização levou médicos e ativistas a se inteirar e se apropriar de teorias a respeito.

Como traz Diniz (2005) o termo humanização também está sujeito a disputas e múltiplos significados, sendo utilizado já há muitas décadas por médicos referência na obstetrícia (tecnocrática) brasileira, como Fernando Magalhães e Jorge Rezende, para os quais humanizar o parto incluía narcose e o uso de fórceps. Estas medidas seriam humanizadoras por serem percebidas como diminuidoras do sofrimento da parturiente e, segundo a autora, se contrapunham ao "[...] modelo anterior da assistência médica, tutelada pela Igreja Católica, [que] descrevia o sofrimento no parto como desígnio divino, pena pelo pecado original, sendo dificultado e mesmo ilegalizado qualquer apoio que aliviasse os riscos e dores do parto" (Diniz, 2005, p. 628).

Já dentro do ideário do movimento pela humanização do parto, abordado neste trabalho, possui em comum a busca por eliminar o sofrimento, porém as causas apontadas para este são outras: não mais a dor inerente ao processo deve ser evitada, mas sim a privação das mulheres de vivenciarem esse momento em sua integridade, que seria roubada por intervenções médicas. Humanização/ humanístico é um termo caro para tradição ocidental, remetendo a um homem/ humanidade universal, neste caso ligado ao humano liberto da história e da cultura, que poderia ser capaz de entrar em contato com seus instintos perdidos. Tal concepção é expressa na fala de Michel Odent, autor importante do movimento de revisão do parto, para quem a busca deve ser por animalizar o parto, retirando dele os elementos identificados com o que seria propriamente humano, a cultura (Tornquist, 2002). Dentro desse ideário o termo também mantém sua multiplicidade, com abordagens baseadas em evidências científicas e/ou em direitos, sejam das pessoas assistidas, sejam dos profissionais da assistência (Diniz, 2005). Tal tensão será abordada na conclusão desse texto.

Olho para esta questão a partir do contexto etnográfico que pesquisei para minha dissertação de mestrado (Mendonça, 2013): o movimento pela 
humanização do parto, as motivações que levam as mulheres a escolherem entre uma forma de parto e outra, as estratégias que estas devem desempenhar para fazer valer sua vontade dentro de um contexto como o brasileiro, em que os nascimentos via cesariana têm ultrapassado consideravelmente os via parto normal e a opinião do médico costuma se sobressair sobre o desejo manifestado pela mulher.

Desta forma este artigo se dedicará também a analisar como as ativistas e demais mulheres se relacionam, respondem e se posicionam com relação a estes discursos médicos, considerando o papel desempenhado por elas como reprodutoras, legitimadoras e construtoras destes discursos, uma vez que, independente da modalidade que venham a preferir, possuirão um discurso que a embase.

Este é um campo teórico e etnográfico de estudos sociais que vêm crescendo no Brasil. Como pioneira temos Salem (2007) que estudou o ideário do casal grávido nos anos 1980. Atualmente as pesquisas realizadas têm seguido por três eixos principais: os estudos sobre parteiras tradicionais; o movimento pela humanização do parto, incluindo o acompanhamento a grupos de gestantes e ativistas e/ou análise da implementação de programas de humanização em maternidades públicas; e trabalhos não necessariamente relacionados à humanização do parto, mas que enfocam as rotinas hospitalares de maternidades e pré-natais, ou ainda se dedicam a pensar sobre a maternidade nos dias de hoje (cf. Del Priore, 1993; Paim, 1998; Brenes, 1999; Hotimsky e Alvarenga, 2002; Diniz, 2001; Scavone, 2004; Tornquist, 2004; Chazan, 2007; Fleicher, 2011; Ribeiro, 2008; Corossacz, 2009; Rezende, 2009; Maia, 2010; Carneiro, 2011; Hirsch, 2014; dentre outras).

Estes trabalhos se dedicam a estudar as disputas entre médicos e doulas, parteiras e/ou enfermeiras obstetras, ou entre serviços de assistência e suas usuárias. Sem desconsiderar estas disputas, minha proposta neste artigo é me debruçar sobre a disputa entre médicos sobre a forma mais "saudável" de parir, uma disputa ocorrida dentro da medicina, "entre iguais".

Como material etnográfico, utilizarei dados de minha pesquisa de campo, obtidos em palestras e encontros de médicos e de ativistas pelo parto normal; serão utilizados também dados da pesquisa de campo virtual, como depoimentos publicados em sites e fóruns online, por profissionais, mães/ gestantes, militantes e eventualmente pais. Esses espaços online são destinados à troca de experiências sobre gestação, família e parto, fazendo-se presente, em todos, certo nível de militância a favor do parto normal, não deixando de haver, porém, fóruns destinados a especificamente a cesáreas. Um terceiro espaço de construção de meus dados foi a consulta a bibliografia publicada por médicos ligados ao movimento pela humanização do parto. 
O material utilizado para contrastar os discursos médicos entre os defensores de cada modalidade contém uma defasagem: devido a minha inserção em campo no movimento pela humanização comparativamente possuo pouco material relacionado aos partidários da cesárea. Porém esta defasagem, além de ser reflexo da minha inserção no grupo pesquisado, vai além disso, evidenciando um elemento importante para pensar a questão: o volume de material escrito disponível, mesmo de conteúdo acadêmico, é altamente desigual, sendo raro encontrar o depoimento de um médico defendendo diretamente a cesárea em detrimento do parto normal, e com o assunto só aparecendo em tom de denúncia às altas taxas praticadas no Brasil (sendo utilizada inclusive a expressão "epidemia de cesáreas"). Nesses textos, por vezes, falas de partidários da cesárea são abordadas com o intuito de crítica.

Penso que uma pesquisa que enfocasse prioritariamente esses dados necessitaria de outro enfoque metodológico, com a imersão em consultórios e/ou escolas de medicina, onde certamente seria possível acessar melhor esses discursos. Afinal, eles existem e se manifestam em diversos círculos, porém continua sendo significativa sua quase total ausência no debate público atual, e mesmo no debate acadêmico médico: durante a pesquisa não encontrei artigos médicos que defendam que a cesárea seja a melhor forma de parto. O que nos instiga a pensar na contradição da modalidade mais realizada ser a menos discutida.

Por fim, este artigo merece mais uma consideração metodológica: apesar dos meus esforços em manter o anonimato de todos os citados nesta pesquisa houve casos em que, pela obrigação em indicar a localização online das citações, $\mathrm{o}$ artifício da troca de nomes simplesmente deixou de funcionar. Outro elemento que impede o anonimato é que usarei aqui referências bibliográficas de médicos do movimento pela humanização, o que os tornariam conhecidos. Assim, neste artigo manterei os nomes próprios dos obstetras Melania Amorin, Ricardo Jones e Jorge Kuhn, bem como o de Jorge Rezende Filho, por sua associação à obra Obstetrícia fundamental, de autoria de seu pai, Jorge Rezende. Nos demais casos utilizarei nomes fictícios.

\section{A construção de verdades científicas}

Penso o debate médico em torno da questão a partir do conceito de campo de Bourdieu, onde os grupos disputam, buscando a posição de domínio: "um espaço - o que eu chamaria de campo - no interior do qual há uma luta pela imposição da definição do jogo e dos trunfos necessários para dominar nesse jogo" (Bourdieu, 1990, p. 119). Pois, como apontam Latour e Woolgar (1997, p. 278), “a atividade científica não se trata da 'natureza', ela é uma 
luta renhida para construir a realidade". O trabalho de campo destes autores, em um laboratório científico, nos mostra que, apesar de a ciência referir a si própria como estudando coisas da natureza - ou seja, coisas que estariam lá, dadas, apenas esperando que os cientistas as desvendassem - ela porém atua enquanto construtora desta realidade, a elaborando passo a passo, com testes e experimentos, e posteriormente apagando este caminho para inserir seus resultados na esfera da natureza.

Laqueur (2001) nos dá uma boa mostra a respeito de como modelos concorrentes buscam ao longo da história definir o que é o corpo. Em Inventando o sexo, o autor realiza uma reconstrução histórica das teorias sobre o sexo ao longo dos séculos, enfatizando que anteriormente prevalecia era uma teoria do sexo único, na qual as mulheres eram "homens virados para dentro", sendo então uma diferença não de espécie, mas apenas de grau: mulheres sendo significadas como homens menos perfeitos. Esse modelo do sexo único passou a mudar por volta do final do século 18, dando lugar a um modelo de dois sexos distintos, que busca na natureza as causas para as diferenças culturais: "uma anatomia da incomensurabilidade substituiu uma metafísica de hierarquia na representação da mulher com relação ao homem" (Laqueur, 2001, p. 17). A passagem de um modelo para o outro não teria sido consequência de uma mudança científica, mas de uma revolução epistêmica e sociopolítica, uma vez que a ciência não atua desvendando fatos naturais, mas construindo. $\mathrm{O}$ objetivo de Laqueur não reside a busca pela teoria mais correta sobre o sexo, mas apontar que os discursos sobre este são produtos de construções culturais, sendo homens e mulheres diferentes exclusivamente dentro do discurso cultural dos dois sexos, como mostra a teoria do sexo único.

Emily Martin é outra autora cujo trabalho se dedica a evidenciar o processo de construção do corpo pela ciência, onde são abordadas de forma histórica diversas teorias sobre o processo de fertilização, mostrando que a construção do papel dos gametas não é um discurso científico neutro, estando impregnado dos papéis sociais atribuídos a homens e mulheres. Assim, através do discurso científico, elementos biológicos como o óvulo e o espermatozoide passam a ser dotados de gênero, atribuindo a eles características de passividade e atividade, respectivamente associadas ao masculino e ao feminino.

De forma semelhante, os discursos médicos aqui abordados possuem em seu fundo o debate sobre a definição do corpo. Visto enquanto natureza por ambos os lados, o que se coloca em questão é como lidar com esta natureza. Seria esse corpo mais uma parte da natureza que o homem deve dominar e controlar através da técnica? Ou seria ele um mecanismo tão perfeitamente 
projetado por ela, cuja melhor forma de lidar seria deixando-o atuar livremente, de acordo com a sua sabedoria ancestral?

É da medicina que provém um dos discursos mais poderosos sobre o corpo. Como afirma Foucault (2002), o poder está atrelado à produção, acumulação, circulação e funcionamento de discursos de verdade, que operam não pelo mecanismo da lei, mas da normalização. O que está em disputa neste campo é qual discurso de verdade prevalecerá, sendo importante observar que ambos os lados se valem de discursos e ideais da medicina - como a diminuição da dor e a preservação da vida e bem-estar - para legitimar suas posições.

A busca pelo discurso de verdade dominante se encontra dentro da disputa colocada no campo médico, no qual aquele que o possuir aumentará o seu poder social, como podemos depreender da citação de Bourdieu (1990, p. 122-123) abaixo:

O campo científico, enquanto sistema de relações objetivas entre posições adquiridas (em lutas anteriores), é o lugar, o espaço de jogo de uma luta concorrencial. O que está em jogo especificamente nessa luta é o monopólio da autoridade científica definida, de maneira inseparável, como capacidade técnica e poder social; ou, se quisermos, o monopólio da competência científica, compreendida enquanto capacidade de falar e agir legitimamente (isto é, de maneira autorizada e com autoridade), que é socialmente outorgada a um agente determinado.

Sobre como um discurso de verdade legitima e empodera uma prática podemos traçar um paralelo com a abordagem feita por Lévi-Strauss (2008, p. 182) a respeito do xamanismo e a figura do feiticeiro em $O$ feiticeiro e sua magia:

Portanto, não há porque duvidar da eficácia de certas práticas mágicas. Porém, ao mesmo tempo, percebe-se que a eficácia da magia implica a crença na magia, que se apresenta sob três aspectos complementares: primeiro, a crença do feiticeiro na eficácia de suas técnicas; depois, a doente de que ele trata ou a vítima que ele persegue, no poder do próprio feiticeiro; e, por fim, a confiança e as exigências da opinião coletiva [...].

Esta passagem nos mostra a importância, para o processo de cura e atendimentos relacionados à saúde, a legitimação social conferida à técnica empregada, que desempenhará grande papel na crença dos agentes envolvidos em sua eficácia. 


\section{Modelo tecnocrático versus modelo humanístico}

Como discurso de partidários da cesárea, utilizarei trechos da postagem em blog do obstetra Jorge Rezende Filho, intitulado A técnica da operação cesariana - novos aspectos, ${ }^{1}$ cujo pai, Jorge Rezende, é autor do livro Obstetrícia (1962), ainda hoje muito utilizado nas escolas de medicina, sendo apelidado de "Rezendão". Na definição do filho, ambos seriam "cesareanistas convictos":

Como meu pai, sou cesarianista convicto. Antes de mais nada, pela universalidade da operação: "a Natureza não pode seguir o seu destino, a arte traçará seu rumo”. Sou cesarianista pelo ser integral a proteção à vida materna e também irrestrita a proteção à vida do concepto. A geração atual de obstetras, na qual me incluo, os jovens egressos de nossas faculdades de Medicina nos últimos 20-30 anos, desaprendeu ou nunca se adestrou nas operações transpelvinas. Quantos de nós sabemos executar uma versão por manobras internas, conhecemos os estorvos dos volteios difíceis, quantos de nós manejamos com desteridade um fórcipe médio, empunhamos, sem temor, o basiótrobo? (grifo meu).

O que podemos observar desse depoimento é primeiramente a filiação enfática à modalidade da cesárea, o destacamento da ética médica de proteção à vida, e a valoração da técnica ("arte") sobre os aspectos fisiológicos do processo. Aborda também elementos da formação dos médicos atuais, onde a ênfase do ensino se dirige para a realização de cesáreas, formando médicos com pouca prática e segurança para realizarem partos normais. Na continuação do texto, o obstetra dedica-se às técnicas com o intuito de romper com a ideia de que, por ser uma cirurgia, esta seria menos segura:

Nos nossos dias, a cesárea atinge as culminâncias de seu aperfeiçoamento técnico. Os riscos da intervenção se amenizam, espelhados no rigor das estatísticas provenientes assim dos grandes centros como dos obscuros hospitais do Terceiro Mundo. Ato de urgência, de urgência extremada bastas vezes, a despeito disso e talvez por isso, a operação cesariana se cristalizou em técnica de simplicidade requintada, a demandar, contudo, uma execução primorosa.

Para esse obstetra, o que torna uma forma de parto melhor do que a outra seria a superioridade de sua técnica. Enquanto a cesárea teria atingido o ápice

\footnotetext{
${ }^{1}$ Disponível em: <www.marciapeltier.com.br/?content=materia\&id=594> (18 fev. 2013).
} 
de seu aperfeiçoamento, a nova geração de médicos não seria treinada o suficiente nas técnicas necessárias para a realização de um parto normal seguro.

Em um fórum de discussão online não-ativista, o tema era se as participantes conheciam algum bebê que teria tido problemas de saúde devido ao nascimento por cesárea. Diversas participantes se posicionaram no sentido de que a ideia de uma saúde mais frágil do bebê que nasce desta forma é um argumento enganoso, utilizado por partidários do parto normal e informado por olhares ultrapassados sobre a modalidade e também sobre o parto normal:

Pois é... as pessoas ainda veem o PC (parto cesáreo) como ele era há 30 anos atrás. Meu antigo GO (ginecologista obstetra) costumava dizer que no Brasil se faz tantos PCs que os médicos se tornaram especialistas. Nem no primeiro mundo se faz essa cirurgia com tanta maestria como aqui. E no que diz respeito à saúde pública (afinal, poucas podem pagar doulas, PNH [parto natural/normal humanizado] etc.) a cesárea é muito mais segura e bem menos traumática. ${ }^{2}$

O que era bom há 40 anos atrás não é bom hoje, mudou muito. ${ }^{3}$

Esta linha de argumento, acionada por mulheres que defendem a cesárea, enfatiza o desenvolvimento técnico como ponto positivo e determinante. Assim, sentem-se seguras em passar pelo procedimento, vendo uma série de vantagens deste sobre o parto normal, tais como evitar as dores do parto e a possibilidade de previsibilidade do evento.

Devido ao enfoque do trabalho de campo posso trazer mais olhares do lado dos defensores do parto normal. Dessa forma abordarei, além das teses defendidas por estes, a conformação das escolas de medicina que operam pelo modelo tecnocrático e o processo de ruptura destes médicos para com seu modelo de formação e a adoção de um novo.

As possibilidades apresentadas nas escolas de medicina oferecem duas opções majoritárias, ambas dentro do modelo tecnocrático: os futuros médicos são direcionados a adotarem uma perspectiva como a do médico acima, de priorizarem as cesáreas, ou um olhar vaginalista, dando preferência ao parto normal, realizado através de diversas intervenções - rejeitadas pelos que defendem a humanização. Ao rejeitarem ambas as possibilidades, estes profissionais devem efetuar o que chamam de "mudança de paradigma", adotando novas práticas e valores. No âmbito do movimento estes profissionais são chamados de médicos humanizados.

\footnotetext{
${ }^{2}$ Retirado de <www.e-familynet.com>.

${ }^{3}$ Retirado de $<$ www.e-familynet.com $>$.
} 
Nem sempre o modelo científico esteve de acordo com os valores da humanização, como bem demonstra a conformação das escolas de Medicina - que abordaremos a seguir - de tal forma que os que não seguiam estes preceitos eram vistos como atrasados no desenvolvimento tecnológico, negando as vantagens deste. Melania Amorin, obstetra paraibana e ativista pela humanização, na palestra intitulada Assistência ao parto baseada em evidências, escolheu como frase de abertura o trecho de uma canção de Lenine:

Éramos uns poetas loucos, místicos

Éramos tudo que não era são

Agora são com dados estatísticos

Os cientistas que nos dão razão.

Este trecho capta o espírito do momento atual em que vivem os médicos humanizados mais velhos, que passaram por um processo mais intuitivo e subjetivo do que alimentado pelas informações vindas de sua formação, tal como o caminho percorrido por Ricardo Jones, médico gaúcho reconhecido pelas ativistas pela humanização do parto, que conta:

Minha entrada na humanização se deu muito antes de compreender o significado e a importância das evidências científicas na condução da assistência ao parto. Tal mudança paradigmática se deu na participação presencial no nascimento dos meus filhos. ${ }^{4}$

Foi através de caminhos pessoais e subjetivos que os obstetras aos quais tive acesso ao longo da pesquisa relatam esta mudança de paradigma, que os fez questionar a prática médica tal como aprenderam em sua formação, buscando modificá-las. Porém, a autoridade da experiência pessoal colocada lado a lado com a autoridade científica, ou utilizada como critério para fundamentá-la, não é característica apenas dos defensores do parto humanizado. Ao ser abordado por uma jornalista para uma matéria a respeito do elevado número de cesáreas, um médico que pediu anonimato afirmou:

Minha filha nasceu por cesárea, minhas sobrinhas também. Se eu achasse tão bom o parto normal teria feito. Claro que se o médico marcar a cirurgia para muito antes, o bebê pode nascer prematuro, com problemas respiratórios, pode complicar sua saúde a longo prazo. Mas no parto normal existe mais risco de asfixia e paralisia cerebral. Se você for perguntar, $90 \%$ dos filhos de médicos nascem por cesárea. ${ }^{5}$

${ }^{4}$ Disponível em: <http://orelhasdevidro.blogspot.com/2012/09/mudanca-de-paradigma.html> (18 fev. 2013).

${ }^{5}$ Retirado de Na hora de fazer não gritou <http://apublica.org/2013/03/na-hora-de-fazer-naogritou/> (11 jan. 2014). 
A resposta do médico alia a ponderação dos riscos de cada modalidade e legitima a cesárea como melhor escolha através de sua experiência familiar, demonstrando assim sua confiança nesta como método seguro. Porém, segundo Patah (2008) em pesquisa realizada na cidade de São Paulo, a incidência de cesáreas entre médicas e esposas de médicos, apesar de altas, não chegariam a $90 \%$, ficando também abaixo também da população estudada. ${ }^{6}$

Após estes questionamentos trazidos pela experiência pessoal os médicos defensores do parto humanizado enveredam pela busca de suporte teórico para a mudança de paradigma, através dos autores do movimento de revisão do parto e de revisões de artigos médicos. Entre seus colegas passam a ser chamados por nomes como "hippies" ou "naturebas", porém os estudos científicos realizados principalmente no exterior começam a se destacar, se colocando ao lado deles.

A Medicina Baseada em Evidências $(\mathrm{MBE})^{7}[\ldots]$ entrou em minha vida por volta de 1994, quando eu era ainda uma jovem obstetra formada dentro do modelo tecnocrático. [...] Quando comecei a pesquisar seriamente sobre esses procedimentos, fiquei espantada ao constatar que não havia nenhuma evidência científica sólida demostrando sua necessidade e efetividade e, ao contrário, já existiam evidências demostrando os seus efeitos deletérios para o binômio mãe-bebê (Amorim, 2012, p. 19).

Apesar de os profissionais passarem por esse chamado momento da virada, em que adentram o universo da humanização, a passagem de um modelo para o outro não é direta e automática, é gradual e muitas vezes mesmo dolorida para os que escolheram trilhar esse caminho. Penso que as escolas de medicina podem ser vistas como instituições com grande poder de imprimir suas visões de mundo, diretamente ligado ao ethos da profissão, tal como discutido por Rojo (2001).

Além das escolas de medicina, a família também pode ser considerada um fator importante para se pensar nessa transmissão de valores no meio médico,

${ }^{6}[\ldots]$ entre as 29 médicas que tinham filhos, $72,4 \%$ delas só tiveram parto cesáreo, enquanto entre as esposas dos obstetras essa taxa foi de $68,4 \%$. Podemos identificar diferença estatisticamente significante entre a taxa de cesárea nas pacientes da amostra nessa tese $(88,4 \%)$ e as taxas dessa cirurgia encontradas nas médicas e nas esposas de médicos [...]. Esse resultado pode sugerir que outros fatores além das preferências médicas devem influenciar a decisão pela cesariana na população em geral" (Patah, 2008, p. 175).

7 "MBE se traduz pela prática da medicina em um contexto em que a experiência clínica é integrada com a capacidade de analisar criticamente e aplicar de forma racional a informação científica de forma a melhorar a qualidade da assistência médica. Na MBE, as dúvidas que surgem ao resolver problemas de pacientes são os principais estímulos para que se procure atualizar os conhecimentos" (Lopes, 2000, p. 285). 
não sendo raro encontrarmos famílias com duas ou três gerações de médicos, incluindo várias gerações com uma mesma especialidade: durante a pesquisa foi frequente encontrar obstetras filhos de obstetras, ou cujo filho estava estudando obstetrícia. Nestes casos o código de valores e o ethos médico encontra uma intersecção com o código e o ethos familiar, sendo portanto aprendido tanto nos espaços da escola de medicina como no convívio familiar.

Assim, o modelo tecnocrático pode atuar por ao menos duas vias na produção do profissional da medicina. Somariam a estas, por fim, a noção corrente na sociedade de que o homem deve controlar a natureza através da tecnologia, tal como discute Davis-Floyd (2003).

Em depoimento para o programa Sala de Notícias, da TV Futura, com o título $O$ futuro do nascer, ${ }^{8}$ o obstetra Jorge Kuhn afirma que os médicos realizam suas residências em hospitais dedicados a atender casos de alto risco, o que leva a uma visão distorcida da normalidade do parto, vendo-o como um evento com potencialidade de erro em que devem interferir para que ocorra com êxito.

No discurso de médicos e ativistas aparece que se livrar desse modelo não é tarefa fácil, como bem captou uma ativista ao dirigir uma pergunta provocativa aos membros da mesa de encerramento do Encontro Nacional de Gestação e Parto Natural Conscientes, ${ }^{9}$ em 2012. Esta mesa foi composta por três jovens médicos, duas mulheres e um homem, que estavam recebendo vastos elogios pelo trabalho de implementação dos preceitos da humanização em uma maternidade pública do Rio de Janeiro. A mesa contava com mais um integrante: fazendo às vezes de moderador e palestrante estava o médico Fernando, um pouco mais velho que os demais, professor destes na residência médica, era a ele a quem atribuíam terem seguido na busca pela humanização da prática obstétrica. A juventude de todo o grupo foi reiteradamente positivada, no sentido de que se necessita de sangue novo para tocar essas questões. Porém a juventude enquanto fase da vida em que mudanças de paradigma são mais possíveis também trazia que estes profissionais ainda apresentavam conflitos, tensões e angústias com relação aos preceitos de sua formação e o modelo que decidiram adotar. A ativista pergunta: "Qual é a prática que vocês ainda fazem que gostariam de abandonar?", ao que os quatro médicos da mesa manifestam seu desejo de diminuírem suas taxas de intervenções:

Eu fico muito ansiosa no expulsivo, toque de 4 em 4 horas, eu quero parar com o toque.

\footnotetext{
${ }^{8}$ Disponivel em: $<$ www.youtube.com/watch? $\mathrm{v}=\mathrm{dTS} 7 \mathrm{KYV}$ V8hw\&feature $=$ share $>(21 \mathrm{jan} .2013)$.

${ }_{9}$ Realizado de 23 a 25 de novembro, na cidade do Rio de Janeiro.
} 
Eu faço a manobra pra liberar o ombro do bebê. Tô tentando me segurar, esperar pra ver se ele vai soltar sozinho, antes de botar a mão. Eu paro, conto mentalmente, mas eu não consigo esperar muito tempo.

Eu tenho medo de parto. Queria lidar melhor, mas não parar, eu tenho medo de parto igual se tem medo de mar.

Eu gostaria de realizar mais partos sem anestesia, fico intrigado com as baixas taxas das enfermeiras. (Fernando)

As respostas dos jovens médicos demonstram a dificuldade de se livrar do modelo intervencionista e a ansiedade que isso gera. A resposta de Fernando aponta para o olhar diferencial de enfermeiras-obstetras/parteiras e médicos sobre o parto, orientado por suas distintas formações, tal como observado por Davis-Floyd (2003), ao relatar que após ouvir ambos os grupos descrevendo situações de parto notou que o primeiro se refere graficamente a beleza e a magia do nascimento, enquanto o segundo foca nas complicações ocorridas. Assim, a autora interpreta que, com o olhar focado para a doença, os médicos do modelo tecnocrático não conseguiriam conceber o parto como um evento fisiológico saudável, buscando interferir, para corrigir o processo e que mesmo renunciando a este paradigma permanece o olhar voltado para as complicações.

Por outro lado, não pode ser ignorado que a cobrança sobre possíveis falhas em um atendimento recai de modo mais intenso sobre os médicos do que sobre as parteiras ou enfermeiras, uma vez que estes são socialmente vistos como aqueles que não podem falhar nunca. Podemos pensar tal cobrança em conjunto com a etnografia realizada por Octavio Bonet (1999), a respeito do aprendizado da biomedicina, na qual o autor aborda a tensão estruturante da disciplina entre os domínios do saber (científico e racional) e o do sentir (emocional e psicológico). Fundada sob uma visão dualista cartesiana de separação entre corpo e mente, entre os dois polos há uma valorização que prioriza o corpo em sua materialidade, porém a dimensão do sentir permanece presente no cuidado e envolvimento com cada paciente. A formação de médicos e enfermeiras pode ser pensada a partir da ênfase diferencial em cada um desses polos, orientando o olhar distinto em relação ao evento do parto.

Outro ponto a ser pensado em relação ao ensino médico enquanto reprodutor de práticas tidas como desnecessárias, e mesmo categorizadas enquanto violência obstétrica é trazido por Escamilla (2012). Em pesquisa realizada no México, com alunos de residência obstétrica cursando uma disciplina de Antropologia Médica, que os levaria a uma maior reflexividade com relação à prática que lhes é ensinada e a uma percepção do modelo 
de ensino enquanto desumano. Segundo a autora, neste hospital-escola muitos procedimentos médicos seriam realizados sem real indicação, com a justificativa de que os alunos precisam praticá-los para aprender. Esse uso pedagógico das intervenções também foi destacado em um debate virtual por uma ativista de Pernambuco.

A partir desta visão, Davis-Floyd (2003) pensa o parto enquanto ritual, onde os procedimentos seriam ritualmente realizados por aqueles que objetivam tornar o evento mais previsível e controlado, reforçando a crença americana do domínio da natureza pela técnica. Apesar de a autora realizar sua análise na sociedade americana, ela observa que esta pode ser estendida a toda parte influenciada pela medicina ocidental.

Por este movimento que observamos em que os médicos devem abandonar a visão dada por sua formação, encontra-se uma tendência em que, ao se defender o parto normal passa-se por uma denúncia do sistema médico vigente, em um nível de reflexividade que procura desconstruir o que foi aprendido para reelaborá-lo.

Desta maneira, grande parte do argumento a favor do parto normal e humanizado se assenta no discurso das Evidências científicas, seja como estratégia ou como crença. Nenhum dos lados desse debate rejeita a ciência, mas cada grupo promove uma visão distinta do que ela seria, de forma a elaborar e dar suporte a suas práticas. De um lado a ciência é vista como tecnologia, a ser incorporada a serviço do maior controle e previsibilidade do evento, do outro são acionados estudos científicos que contradizem esta visão, defendendo que maior tecnologia não é sinônimo de melhor assistência ao parto e que muitas dessas intervenções são praticadas indiscriminadamente.

A Medicina Baseada em Evidências opera da mesma forma que Latour define a atividade científica como um todo, tratando as "descobertas" como evidências naturais a partir do momento em que são aceitas pelos pares, apagando seu aspecto de construção e as inserindo na natureza. As evidências científicas acionadas provêm principalmente da Cochrane Library. Esta biblioteca virtual é uma iniciativa de colaboração internacional, fundada em 1993, a partir do questionamento de seu idealizador Iain Chalmers a respeito da prática médica e nas dúvidas surgidas em seu exercício. Partindo de sua área de atuação, a obstetrícia, formou um grupo de colaboração internacional para reunir pesquisas a respeito das práticas obstétricas, com o intuito de conseguir uma definição do que seriam práticas necessárias e desnecessárias em cada caso e quando elas seriam prejudiciais.

Hoje a Cochrane Library produz revisões sistemáticas da produção científica internacional de todas as especialidades médicas, constituindo-se 
enquanto referência científica fundamental para toda a área de cuidados da saúde. ${ }^{10}$ É importante destacar que a motivação para a criação desta biblioteca esta imbuída dos sentimentos que viemos tratando aqui como motivadores da mudança de paradigma médico e que não é coincidência que o projeto tenha partido da obstetrícia. Parece-me que as pontas do sistema de cuidados médicos - nascimento e morte - ao não se enquadrarem propriamente dentro da noção de doença, foram capazes de iniciar a discussão a respeito das intervenções e patologização desses eventos, como podemos observar em diálogo com o trabalho de Menezes (2004), com doentes terminais e a busca por uma boa morte.

As ativistas também seguem esta linha de buscar suporte nas evidências científicas, alegando "minha opinião muda com nova informação", em crítica aos que ignorariam estes estudos, apontando que estes permaneceriam presos a uma mentalidade estática e não questionadora. O suporte científico também é importante para contrapor estereótipos associados às mulheres que optam por esse tipo de parto: "bruxas", "índias", "hippies", "naturebas" etc. Assim, é comum que as ativistas busquem dados estatísticos e artigos médicos para reforçar seus argumentos.

O momento em que realizei este trabalho foi de considerável efervescência destas discussões, uma vez que o ativismo em prol do direito da mulher escolher onde e como ter seus filhos veio se intensificando, havendo embates com os conselhos de medicina locais e uma boa exposição na mídia. A maior exposição do tema demandou desses grupos que, além de intensificarem suas ações, buscassem novas abordagens para atrair mais adeptos.

Nesse sentido, os argumentos de duas ativistas, em um debate realizado para pensar novos rumos de ação, são interessantes para pensarmos a apropriação e rejeição de discursos médicos. Uma ativista mais recente iniciou o assunto, questionando o uso feito pelas ativistas de termos médicos, que dificultariam o entendimento de leigos às reivindicações:

Você tem que estudar exaustivamente pra ter um parto. Quantas pessoas vão fazer isso? Eu não fiz isso no meu primeiro filho e tive uma cesárea desnecessária. Eu só fui me familiarizar com essa discussão há pouco mais de um ano e meio. Acho que o vocabulário que as ativistas usam é muito especializado, dificulta a compreensão. Tipo Kristeller, eu via em todo lugar, mas não sabia o que era, só fui descobrir na semana passada. Nós temos de dizer 'tão subindo em cima da sua barriga!', porque Kristeller assim, o nome, é até bonitinho.

\footnotetext{
${ }^{10}$ Informações obtidas através do vídeo comemorativo de 20 anos da Cochrane Library, disponível em $<$ www.youtube.com/watch? $v=0$ Ji-wsSfQH0\&feature=youtu.be $>$ e no site da biblioteca: $<$ www.cochrane.org/> (17 fev. 2013).
} 
Uma ativista mais antiga respondeu que o uso deste vocabulário mais especializado se deve ao fato da militância ter se iniciado em conjunto com médicos defensores do paradigma humanizado, se apropriando do vocabulário, mas destacou a importância da abertura da linguagem para atrair mais adeptos.

Apesar destas novas preocupações, não se pode deixar de observar que o acionamento de um discurso utilizando termos especializados pode empoderar as mulheres em uma negociação direta com seu médico, sendo este aprendizado considerado importante para aquelas que buscam um parto humanizado:

Eu tive de fazer uma verdadeira maratona para conseguir meu parto. Sabia que as cesarianas eram regra, mas não que era tanto assim. Os médicos te dizem: "Vamos tentar um parto normal", como se fosse o mais difícil, como se exigisse condições. Ora, o "normal" não é ser normal e a cirurgia só acontecer se algo der errado? O fato é que eu tive de convencer, barganhar, ameaçar trocar de médico para conseguir que fosse normal. Percebi que precisaria me informar horrores, me apropriar do processo, para que quando chegasse o momento ninguém pudesse me enrolar com desculpas como as que eu ouvia de amigas justificando cesáreas. E nesta viagem eu aprendi muitas coisas sobre parto. Tantas que teria sido capaz de fazer o meu sozinha. ${ }^{11}$

Essa incorporação de informações técnicas é uma importante estratégia para o grupo, tanto que parte considerável das ações do movimento é a divulgação a respeito de informações sobre o que consideram boas práticas obstétricas.

Vale destacar que em caso de debates entre os dois grupos, quando este é despertado em alguma polêmica online, os defensores do modelo tecnocrático não conseguem ser tão eficientes em indicar referências científicas quanto os obstetras e ativistas pela humanização, a partir do que podemos supor a) que não existem realmente referências científicas atuais em volume significativo que deem suporte a esse modelo, ou b) que a busca dessas referências atualizadas não é uma preocupação para este grupo.

Como se pode ver o debate não é simplesmente entre partidários de uma modalidade ou outra, mas sim entre defensores de dois modelos, o tecnocrático e o humanista, não se tratando da modalidade em si, mas a forma como ela é executada. Para as pessoas ligadas ao movimento pela humanização existe uma importante distinção entre os médicos humanizados e os já mencionados

\footnotetext{
${ }^{11}$ Retirado da matéria "Eu fiz o parto do meu filho, não o médico" - Revista Época, disponível em $<$ http://revistaepoca.globo.com/Revista/Epoca/0,EMI204610-15230,00.html>.
} 
"vaginalistas" - que apesar de considerarem o parto vaginal uma opção melhor do que a cesárea, o realizariam fora da concepção que prioriza o mínimo de intervenções, de modo que os primeiros denominam como violência obstétrica diversas práticas dos segundos. Como podemos observar na definição feita de violência obstétrica por Escamilla (2012), boa parte dos procedimentos colocados nesta definição são realizados por vaginalistas em partos normais, que devido a estes recebem das ativistas a alcunha de "parto frank":12

Diversas prácticas relacionadas con la atención del parto se han englobado bajo el término de violencia obstétrica como realizar cesáreas no indicadas, el uso excesivo o innecesario de oxitocina [hormônio sintético para a aceleração do parto], la práctica de tricotomía [depilação total dos pelos], aminiotomía [ruptura artificial das membranas fetais (bolsa d'água)] o episiotomía [incisão medial ou lateral da vulva durante o parto, a fim de evitar lacerações] de rutina, la aplicación de enema [introdução no reto de produtos medicamentosos com a finalidade de provocar a evacuação de matérias fecais retidas no intestino], el no permitir a la paciente elegir la posición durante el parto, la omisión de información, llevar a cabo procedimientos sin explicarle las opciones y/o sin obtener su consentimiento y la esterilización o aplicación de métodos anticonceptivos temporales - como la inserción de dispositivo intrauterino -, sin previa consejería ni autorización de la mujer (Escamilla, 2012, p. 4 - notas minhas). ${ }^{13}$

Assim podemos pensar na defesa do parto normal feita por obstetras e ativistas como uma defesa do modelo humanizado de assistência, que Jones definiu sobre o seguinte tripé conceitual:

O protagonismo restituído à mulher, sem o qual estaremos apenas 'sofisticando a tutela', imposta milenarmente pelo patriarcado.

Uma visão integrativa e interdisciplinar do parto, retirando deste o caráter de 'processo biológico', e alçando-o ao patamar de 'evento humano', onde os aspectos emocionais, fisiológicos, sociais, culturais e espirituais são igualmente valorizados, e suas específicas necessidades atendidas.

Uma vinculação visceral com a Medicina Baseada em Evidências, deixando claro que o movimento de 'Humanização do Nascimento', que hoje em dia se espalha pelo mundo inteiro, funciona sob o 'Império da Razão', e não é movido por crenças religiosas, ideias místicas ou pressupostos fantasiosos.

\footnotetext{
${ }^{12}$ Em referência ao monstro do Dr. Frankenstein, da obra de Mary Shelley, cujo o corpo foi criado através da sutura de partes humanas.

${ }^{13}$ Fonte: Dicionário digital de termos médicos, disponível em: <www.pdamed.com.br/diciomed/ pdamed_0001_06822.php> (25 fev. 2013).
} 
É neste contexto de oposição ao modelo tecnocrático que a demanda pelo parto domiciliar pode ser entendida: o hospital como instituição conformada por este modelo não poderia atender integralmente os desejos de quem busca um parto humanizado, dessa forma, a casa aparece como um espaço livre da influência intervencionista deste modelo.

\title{
O surgimento de novos profissionais e a constante construção do modelo humanizado
}

A própria figura da doula também só faz sentido dentro da concepção do modelo humanizado, uma vez que a proposta de oferecer apoio e amparo físico e emocional à parturiente só se apresenta como necessidade dentro de um modelo que aspire a não despersonalização daquele que recebe a assistência à saúde. O uso recente da denominação "doula" mostra como sua emergência está diretamente ligada ao movimento pela humanização, como ouvi de Valéria, doula expoente do movimento, que atua na profissão desde o final da década de 1970 "Eu sou doula desde o tempo em que nem se chamava assim", ou quando perguntei a outra doula experiente se ela havia começado sua carreira como doula "Quando eu comecei não se chamava assim, minha formação foi como assistente de amamentação".

No lançamento de seu livro Entre as orelhas, Jones (2012) contou como percebeu que para exercer realmente a humanização precisaria do auxílio das doulas. Relata que, ao visitar uma livraria, um livro literalmente cai sobre sua cabeça: era um livro de Michel Odent, autor do movimento de revisão do parto, onde encontrou uma foto que o tocou profundamente: uma parteira abraçada a sua paciente nua. Davis-Floyd (2012, p. 15), comentando esta história, a completa:

\begin{abstract}
Ali percebera o seu limite, a margem; a sua borda pessoal. Não havia como, em sua prática de obstetra humanizado solitário, oferecer aquele tipo de integração, aquela conexão e o nível de intimidade feminina que aquelas duas mulheres apresentavam. [...] 'Bem, se eu quero mesmo chegar a esse nível de atenção integradora do parto, oferecendo um suporte que vai além das questões fisiológicas e mecânicas, eu precisarei do auxílio das mulheres nesta tarefa'.
\end{abstract}

A doula traria então uma integração do feminino para o parto, de forma que não é concebida a possibilidade de um homem exercer a função, uma vez que a noção de feminilidade aqui abordada é a de algo intrinsecamente ligado à essência da mulher. A partir de Tornquist (2002) problematizarei a essencialização de gênero presente neste ideário na conclusão deste artigo. 
Sendo a doula uma profissional cujo surgimento é imbuído das noções de humanização, são constantes os embates destas e médicos e/ou hospitais do modelo tecnocrático. Um caso recente e emblemático ocorreu ao final de janeiro de 2013, quando as duas maiores maternidades de São Paulo criaram medidas para restringir a presença de doulas nas salas de parto, passando a considerá-las na categoria de acompanhante. Como nestas maternidades era permitido que apenas uma pessoa acompanhasse a mulher no parto, dentro destas medidas a mulher deveria escolher entre a presença do marido ou da doula.

Houve grande mobilização a partir do caso, sendo organizada uma marcha pelo direito da mulher em contar com uma doula na sala de parto. Realizada em São Paulo, esta manifestação contou com a participação de cerca de mil manifestantes, segundo matéria da Folha de São Paulo. ${ }^{14}$ Após as mobilizações, as maternidades recuaram parcialmente em suas posições, realizando um cadastro de doulas que teriam autorização para atuar dentro destas maternidades. Esta decisão agradou apenas parcialmente as ativistas, uma vez que as doulas que não estivessem cadastradas somente poderiam atuar enquanto acompanhante.

Apesar desse conflito em potencial entre doulas e maternidades/equipes médicas é ressaltado que a postura ativista das doulas não deve ser trazida para dentro da sala de parto. Valéria, em seus cursos de formação para doulas, destaca que no momento de sua atuação a doula não deve ser ativista, deve se concentrar no seu trabalho, sem questionar ou entrar em conflito com a equipe médica.

Assim como emerge este novo profissional as práticas humanizadas são objetos constantes de reflexão e escrutínio. Cada caso pode levantar o questionamento "essa é uma postura verdadeiramente humanizada?", no qual através do embate entre posições vai sendo definido qual profissional tem o direito de ser nomeado humanizado, qual é apenas vaginalista e qual seria ainda um cesarista disfarçado. A opção por realizar cesáreas eletivas costuma ser o grande canal divisor entre o modelo tecnocrático e o humanizado, se argumentando que um profissional humanizado não realizaria cesáreas a não ser em caso de real indicação fisiológica para elas. Os profissionais que ficam no limiar da humanização, segundo a classificação das ativistas, seriam aqueles que consideram, além dos aspectos fisiológicos, também a esfera emocional e o desejo manifestado pela mulher, realizando assim "cesáreas a pedido".

\footnotetext{
${ }^{14}$ Manifestação na av. Paulista pede acesso de doulas a salas de parto, publicada em 3 fev. 2013.
} 


\section{Conclusão}

Eis o paradoxo do ideário da humanização do parto. A preponderância que as "reais indicações para uma cesárea" têm - frente ao parto pensado como evento integral e humano e principalmente ao protagonismo e a autonomia da mulher em decidir como terá seus filhos - seria melhor traduzido na imagem de uma pirâmide hierárquica do que na de um tripé conceitual, tal como definido por Jones. Cabe indagar, a partir da fala do médico, se o que vem sendo defendido pelos humanizados ortodoxos não seria apenas uma sofisticação da tutela promovida pelo saber médico sobre o corpo feminino. Sem promover reais mudanças em relação ao saber biomédico clássico, no qual a autonomia da mulher poderia ir apenas até onde o médico permitir e ao encontro desta, permanecendo ser este a ter a última palavra, não a mulher.

Da mesma forma pode ser pensada a postura das ativistas. Ao reivindicarem que a escolha pela forma de parto deve ser embasada em informações de qualidade - ou seja, as propagadas pelo movimento pela humanização que indicam claramente o parto normal como mais benéfico na maior parte dos casos - tal colocação das evidências científicas no topo da pirâmide do que deveria orientar a escolha das mulheres pode resultar na desqualificação e moralização, por parte das ativistas, daquelas que derem preferência para outros critérios ao efetuarem sua escolha.

Podemos pensar esse paradoxo em conjunto com o que Tornquist (2002) denomina como armadilhas da humanização do parto: o discurso em torno da essência feminina, sua associação com a natureza que - além de não provocar uma ruptura com o pensamento biomédico clássico - reproduz categorias como a de instinto materno. Cabe a reflexão sobre os limites e desdobramentos deste discurso, considerando que as mulheres continuarão se defrontando, por um lado com um saber científico que lhes dita o que devem fazer, pelo outro com seus desejos e as limitações de seus campos de possibilidades.

Como trazido por Latour e Woolgar (1997) e Bourdieu (1990), a ciência - e, portanto, as evidências científicas - não é algo dado, mas sim construído de acordo com os interesses dos atores do campo. Como atores buscando sua legitimação em um campo, os defensores da humanização são compelidos a atuar pelas regras dos que dominam o jogo, de modo que o assentamento no argumento científico, enfatizando levá-lo mais a sério do que os que defendem o modelo tecnocrático, vem sendo um modo eficaz de conquistar espaço e influência. Porém não sem custos caros ao ideário da humanização do parto como um todo, sobrepondo as importantes questões relativas ao protagonismo e autonomia das mulheres. 


\section{Referências}

AMORIM, Melania. Prefácio. In: Ricardo Jones. Entre as orelhas: histórias de parto. Porto Alegre: Ideias a Granel, 2012. p. 19-23.

BRENES, Anayansi Correa. História da parturição no Brasil, século XIX. Cadernos de Saúde Pública, v. 7, n. 2, p. 135-149, 1999.

BONET, Octavio. Saber e sentir: uma etnografia da aprendizagem da biomedicina. Physis: Rev. Saúde Coletiva, Rio de Janeiro, v. 9, n. 1, p. 123-150, 1999.

BOURDIEU, Pierre. Coisas ditas. São Paulo: Brasiliense, 1990.

CARNEIRO, Rosamaria Giatti. Cenas de parto e politicas do corpo: uma etnografia de experiências femininas de parto humanizado. Tese de doutorado, Programa de Pósgraduação em Antropologia Social. IFCH - Universidade Estadual de Campinas, 2011.

CHAZAN, Lilian Krakowski. "Meio quilo de gente”: um estudo antropológico sobre ultra-som obstétrico. Rio de Janeiro: Ed. Fiocruz, 2007.

COROSSACZ, Valeria Ribeiro. O corpo da Nação. Rio de Janeiro: Editora UFRJ, 2009.

DAVIS-FLOYD, Robbie. Birth as an American rite of passage. Berkeley: University California Press, 2003.

DAVIS-FLOYD, Robbie. Prefácio. In: Ricardo Jones. Memórias do homem de vidro: reminiscências de um obstetra humanista. Porto Alegre: Ideias a Granel, 2012. p. 21-30.

DEL PRIORE, Mary. Ao sul do corpo: condição feminina, maternidades e mentalidades no Brasil colônia. Rio de Janeiro: José Olympo, 1993.

DICIONÁRIO digital de termos médicos <www.pdamed.com.br/diciomed/ pdamed_0001_06822.php> (18 fev. 2013).

DINIZ, Carmen Simone Grilo. Entre a técnica e os direitos humanos: possibilidades e limites da humanização da assistência ao parto. Tese de doutorado, Faculdade de Medicina da Universidade de São Paulo. Departamento de Medicina Preventiva, São Paulo, 2001.

DINIZ, Carmen Simone Grilo. Humanização da assistência ao parto no Brasil: os muitos sentidos de um movimento. Ciência \& Saúde Coletiva, v. 10, n. 3, p. 627-637, 2005.

ESCAMILLA, Bianca Vargas. Violencia obstétrica como resultado del proceso de medicalización y deshumanización de la formación y la práctica médica. Actas del Tercer Congreso Latinoamericano de Antropología ALA 2012. Santiago de Chile, 5 al 10 de noviembre.

EU FIZ O PARTO do meu filho, não o médico. Revista Época, 24 jan. $2011<$ http:// revistaepoca.globo.com/Revista/Epoca/0,EMI204610-15230,00.html>.

E-FAMILYNET. <www.e-familynet.com> (18 fev. 2013).

FLEISCHER, Soraya. Parteiras, Buchudas e Aperreios. Uma etnografia do cuidado obstétrico não oficial na cidade de Melgaço, Pará. Santa Cruz do Sul, Edunisc, 2011.

FOUCAULT, Michel. Em defesa da Sociedade. São Paulo: Martins Fontes, 2002. 
HOTIMSKY. Sonia Nussenzweig; ALVARENGA, Augusta Thereza de. A definição do acompanhante no parto: uma questão ideológica? Revista de Estudos Feministas, v. 10, n. 2, p. 461-481, 2002.

HIRSCH, Olivia Nogueira. O parto "natural” "e "humanizado”: um estudo comparativo entre mulheres de camadas populares e médias no Rio de Janeiro. Tese de doutorado, Programa de Pós-graduação em Ciências Sociais da PUC-Rio, 2014.

JONES. Ricardo. Entre as orelhas. Porto Alegre: Ideias a Granel, 2012.

LAQUEUR, Thomas. Inventando o sexo. Rio de Janeiro: Relume Dumará, 2001.

LATOUR, Bruno; WOOLGAR, Steve. Vida de laboratório: a produção dos fatos científicos. Rio de Janeiro: Relume Dumará, 1997.

LÉVI-STRAUSS, Claude. O feiticeiro e sua magia. In: Claude Lévi-Strauss. Antropologia estrutural. São Paulo: Cosac Naify, 2008. p. 181-200.

LOPES, A. A. Medicina baseada em evidências: a arte de aplicar o conhecimento científico na prática clínica. Revista da Associação Médica Brasileira, v. 46, n. 3, p. 285-288, 2000.

MAIA, Mônica Bara. Humanização do parto: política pública, comportamento organizacional e ethos profissional. Rio de Janeiro: Fiocruz, 2010.

MANIFESTAÇÃO na av. Paulista pede acesso de doulas a salas de parto. Folha de São Paulo, 3 fev. 2013 <www1.folha.uol.com.br/cotidiano/1225276-manifestacao-na-avpaulista-pede-acesso-de-doulas-a-salas-de-parto.shtml $>$.

MARCIA Peltier. <Www.marciapeltier.com.br> (18 fev. 2013).

MARTIN, Emily. The egg and the sperm: how science has constructed a romance based on stereotipycal male-female roles. In: L. Lamphere; H. Ragone; P. Zavella (Orgs.). Situated lives. Nem York: Routledge, 1997. p. 85-98.

MENDONÇA, Sara Sousa. Mudando a forma de nascer: agência e construções de verdades entre ativistas pela humanização do parto. 2013. Dissertação de mestrado, Programa de Pós-graduação em Antropologia, Universidade Federal Fluminense, Niterói.

MENEZES, Rachel. Em busca da boa morte: antropologia dos cuidados paliativos. Rio de Janeiro: Garamond: Fiocruz, 2004.

NA HORA de fazer não gritou. Agência de reportagem e jornalismo investigativo, 25 mar. $2013<$ http://apublica.org/2013/03/na-hora-de-fazer-nao-gritou/> (11 jan. 2014).

ORELHAS de vidro <www.orelhasdevidro.blogspot.com.br> (18 fev. 2013).

PAIM, Heloisa Helena Salvatti. Marcas no corpo: gravidez e maternidade em grupos populares. In: L. F. D. Duarte; O. F. Leal (Orgs.). Doença, sofrimento, perturbação: perspectivas etnográficas. Rio de Janeiro: Fiocruz, 1998. p. 31-47.

PATAH, Luciano Eduardo Maluf. Por que 90\%? Uma análise das taxas de cesárea em serviços hospitalares privados do município de São Paulo. Tese de doutorado, Escola de Administração de Empresas de São Paulo, Fundação Getúlio Vargas, São Paulo, 2008.

REZENDE, Claudia Barcellos. Ansiedade e medo na experiência da gravidez. In: VIII Reunião de Antropologia do Mercosul, 2009, Buenos Aires. RAM 2009. 
REZENDE, Jorge. Obstetrícia. Rio de Janeiro: Livraria Editora Guanabara Koogan S.A., 1962.

RIBEIRO, Fernanda Bittencourt. Maternidades à margem: Gravidez e nascimento numa instituição de proteção à infância. História. Questões e Debates, v. 47, n. 0 , p. 139-155, $2008<$ dx.doi.org/10.5380/his.v47i0.12114>.

ROJO, Luiz Fernando. Os diversos tons do branco: relações de amizade entre estudantes de medicina. Rio de Janeiro: Litteris Ed., 2001.

SALA de Notícias 1: O futuro do nascer. Canal Futura, 2013, 14'24" <www.youtube. com/watch? $\mathrm{v}=\mathrm{dTS} 7 \mathrm{KYVU}$ Vhw\&feature $=$ share $>$ (28 mar. 2013).

SALEM, Tania. O casal grávido: disposições e dilemas da parceria igualitária. Rio de Janeiro: Ed. FGV, 2007.

SCAVONE, Lucila. Dar a vida e cuidar da vida: feminismo e Ciências Sociais. São Paulo: Editora Unesp, 2004.

TORNQUIST, Carmen Susana. Parto e poder: o movimento de humanização do parto no Brasil. Tese de doutorado, PPGAS-UFSC, Florianópolis, 2004.

TORNQUIST, Carmen Susana. Armadilhas da nova era: natureza e maternidade no ideário da humanização do parto. Estudos Feministas, v. 10, n. 2, p. 483-492, 2002.

TWENTY years of The Cochrane Collaboration: looking back on the search for evidence, 2013. 11'35" <www.youtube.com/watch?v=0Ji-wsSfQH0\&feature=youtu. be $\% 20$ e $>$ (28 mar. 2013).

Recebido em: 6 nov. 2014

Aprovado em: 12 jan. 2015

Autora correspondente:

Sara Sousa Mendonça

Universidade Federal Fluminense

Campus do Gragoatá

Rua Prof. Marcos Waldemar de Freitas Reis, $\mathrm{s} / \mathrm{n}^{\mathrm{O}}$

Bloco P, 2º andar, sala 203 - São Domingos

24210-350 - Niterói, RJ 